\title{
Reversal of Heart and Respiratory Failure Following Accidental Exposure to Hydrogen Sulfide: Case Report
}

\author{
David Silva $^{\mathrm{a}, \mathrm{d}}$, Nuno Correia ${ }^{\mathrm{b}}$, Alice Pinheiro ${ }^{\mathrm{a}}$, Miguel Marques ${ }^{\mathrm{a}}$, Gustavo Barbosa ${ }^{\mathrm{c}}$, \\ Carla Melo ${ }^{a}$, Mario Esteves ${ }^{\mathrm{a}}$, Augusto Duarte ${ }^{\mathrm{a}}$
}

\begin{abstract}
Risks of exposure to toxic gases are well recognized during work in sewers, the principal hazards resulting from hypoxia due to the accumulation of methane, carbon dioxide, or hydrogen sulfide and explosive risk as a result of flammable gases. Hydrogen sulfide $\left(\mathrm{H}_{2} \mathrm{~S}\right)$ is a colourless rotten egg odour gas resulting from organic matter decomposition. The severity of $\mathrm{H}_{2} \mathrm{~S}$ intoxication depends on the concentration and duration of exposure and the outcome may be fatal. We report the case of a 59-year-old male patient who was acutely exposed to sewers gases following an accidental leak in a swine facility nearly eighteen hours before. He presented to the emergency room with respiratory complaints and chest pain, and rapidly developed a multi-organ dysfunction syndrome with severe cardio-respiratory failure. No methaemoglobinemia was detected and $\mathrm{H}_{2} \mathrm{~S}$ was presumed to be the major implicated toxic substance. Treatment strategy relied mostly on supportive measures with a successful outcome. Approach to victims of exposure to sewers gases should recall the strong possibility of poisoning by $\mathrm{H}_{2} \mathrm{~S}$, a life-threatening condition. Since laboratorial dosing of sulfide compounds is not readily available, the initial approach is based on a high clinical suspicion. $\mathrm{H}_{2} \mathrm{~S}$ direct toxicity and cellular hypoxic induction may rapidly lead to multi-organic dysfunction and death. Evidence from case reports suggests that early treatment with
\end{abstract}

Manuscript accepted for publication November 21, 2011

\footnotetext{
${ }^{a}$ Internal Medicine Service. Centro Hospitalar Medio Ave. Unidade Famalicao. Rua Cupertino de Miranda, Apartado 31, 4761-917 Vila Nova de Famalicao, Portugal

${ }^{\mathrm{b}}$ Internal Medicine Service. Hospital de Sao Joao. Alameda Prof. Hernani Monteiro, 4200-319 Porto, Portugal

${ }^{\mathrm{c} I n t e r n a l ~ M e d i c i n e ~ S e r v i c e . ~ C e n t r o ~ H o s p i t a l a r ~ d o ~ T a m e g a ~ e ~ S o u s a . ~}$ Unidade Padre Americo, Lugar do Tapadinho, 4564-007 Guilhufe, Penafiel, Portugal

${ }^{\mathrm{d} C}$ Corresponding author: David Silva, Rua da Gandra No702 4805-017

Barco Guimaraes Portugal. Email: davidalexsilva@gmail.com
}

doi: $10.4021 / \mathrm{jmc} 397 \mathrm{w}$ nitrites, hyperbaric oxygen therapy and hydroxocobalamin may be beneficial. To the present date, supportive treatment remains the mainstay of care.

Keywords: Hydrogen sulfide; Poisoning; Sewers gases.

\section{Introduction}

Risks of exposure to toxic gases are well recognized during work in sewers, the principal hazards resulting from hypoxia due to the accumulation of methane, carbon dioxide, hydrogen sulfide $\left(\mathrm{H}_{2} \mathrm{~S}\right)$ and explosive risk as a result of flammable gases. Standard safety procedures usually reflect these hazards [1].

Hydrogen sulfide is a highly toxic, inflammable, fatsoluble and colourless gas, readily recognized at low concentrations by its "rotten egg" odour. It results from organic matter decomposition, industrial refinery or volcanic hot springs [2-5]. It has been referred to as the "knock down gas" because it can cause immediate loss of consciousness and death if inhaled in high concentrations $[6,7]$.

Most reported cases have occurred following incidents in petrochemical industry (petroleum, chemical, mining, heavy water and metal refining), agriculture, sewage work, natural gas production, natural incidents in volcanic regions and hot springs $[8,9]$.

Prevalence of $\mathrm{H}_{2} \mathrm{~S}$ exposure has increased markedly with the development of swine confinement facilities [10, 11]. Dramatically, 1007 cases of suicide attempts with $\mathrm{H}_{2} \mathrm{~S}$ were reported in 2008 in Japan, presumably due to the availability of information of this substance over the internet regarding a new home-made method of making the gas $[4,12]$. Mortality varies from 2 to $6 \%$ according to different series [13].

In Portugal, there is no available official statistical data regarding $\mathrm{H}_{2} \mathrm{~S}$ intoxication. Data from a major Portuguese hospital regarding intoxications between 2004 and 2009 reported only 4 cases with a diagnostic classification in the category of exposure to "gases, fumes, or vapours" of the International Disease Classification's, corresponding to a total percentage of $2 \%(n=195)[14]$. 
Table 1. Arterial Blood Analysis Result Without Oxygen Supplementation

\begin{tabular}{lll}
\hline Parameter & Value & Normal range \\
\hline $\mathrm{pH}$ & 7.45 & $7.35-7.45$ \\
$\mathrm{pCO}_{2}(\mathrm{mmHg})$ & 28 & $35-45$ \\
\hline $\mathrm{pO}_{2}(\mathrm{mmHg})$ & 57 & $80-100$ \\
$\mathrm{SO}_{2}(\%)$ & 91 & $>95$ \\
$\mathrm{HCO}_{3}(\mathrm{mmol} / \mathrm{L})$ & 19.5 & $22-26$ \\
$\mathrm{Lactates}(\mathrm{mmol} / \mathrm{L})$ & 3.7 & $0.5-2$ \\
\hline
\end{tabular}

We report the case of a patient who developed a multiorganic dysfunction syndrome secondary to acute exposure to sewer gas and discuss current treatment options and possible sequelae.

\section{Case Presentation}

A 57-year-old male hog farm worker, with an irrelevant past medical history, presented to our Emergency Department (ED) complaining of shortness of breath, dry cough, mild haemoptysis and chest pain. The symptoms developed after an accidental exposure to a leak of sewer gas nearly eighteen hours before admission. A "rotten eggs" body odour was evident despite previous full body wash.

On physical examination, the patient presented with severe respiratory distress. Blood pressure and pulse rate were 109/74 $\mathrm{mmHg}$ and $110 \mathrm{bpm}$, temperature $36.2^{\circ} \mathrm{C}$ and respiratory rate $36 \mathrm{cpm}$. Bilateral expiratory fine crackles were present on both lung bases. Neurological exam was unremarkable.

Arterial blood gas analysis revealed a type I respiratory failure with $\mathrm{PaO}_{2} / \mathrm{FIO}_{2}$ ratio of 271 (Table 1). The electrocardiogram showed a sinus rhythm and global ST-segment elevation (leads I-III, aVF and V3-6).

Blood analysis showed a high inflammatory response, rhabdomyolysis, myocardial, hepatic and renal damage (Table 2). A predominant right-sided diffuse bilateral infiltrate was observed on chest X-ray (Fig. 1A) and a lung CT scan demonstrated a diffuse ground glass pattern with peribronchovascular bilateral infiltrate (Fig. 2A).

Echocardiogram revealed severe depression of left ventricular function with global hipokinesia and a low grade mitral and aortic insufficiency, with dilated left cameras.

The patient was started on non-invasive bi-level positive pressure ventilation and transferred into an Intermediate Care Unit. Further treatment strategy included fluids, largespectrum antibiotics, corticoids and appropriate oxygen supplementation. Weaning support measures were kept up for 12 days until discharge. Day 7 chest X-ray (Fig. 1B), lung CT scan and discharge echocardiogram showed no significant changes in comparison to admissionfindings. Clinical course was favourable and biomarkers of organ dysfunction gradually normalized.

The patient received close follow-up at the Internal Medicine Outpatient Clinic. At 3-month reassessment the patient remained asymptomatic: full recovery of pulmonary parenchyma lesions (Fig. 1C, 2B) and improvement of left ventricular heart function (ejection fraction of $60 \%$ ) was documented. At 1-year post-exposure, no long-term sequelae have yet been detected.

\section{Discussion}

Unknown toxic gases may be encountered within sewers. Currently, the usual gas detection equipment is unable to identify the wide range of potential hazards. Any unidentified and unusual odour represents a hazard until proven otherwise [1]. Although use of gas detection equipment remains important for the readily identified hazards, adequate protection for workers and medical teams in such scenarios must be provided by appropriate training and use of positive pressure breathing apparatus [1].

The severity of $\mathrm{H}_{2} \mathrm{~S}$ intoxication depends on the concentration and duration of exposure with a wide variety of symptoms. At levels as low as 0.05 ppm it is described as a pungent, "rotten egg" gas. Under 100 ppm it may be sensed as a sweet odour. Outstandingly, its warning odour is lost at higher concentrations because of olfactory nerve paralysis [2-5]. $\mathrm{H}_{2} \mathrm{~S}$ is rapidly absorbed by the respiratory tract at concentrations of $250 \mathrm{ppm}$ or higher and its direct toxicity result from induction of a hypoxic state due to respiratory blockade at a cellular level by inhibiting the mitochondrial cytochrome oxidase. Mental status depression and cardiac arrest within 30-60 minutes occur with exposure to concentrations above 
Table 2. Venous Blood Sample Results

\begin{tabular}{|c|c|c|}
\hline Parameter & Value & Normal range \\
\hline Haemoglobin $(\mathrm{g} / \mathrm{dL})$ & 17.6 & $13-18$ \\
\hline Platelets $\left(\mathrm{x} 10^{3} / \mu \mathrm{L}\right)$ & 422 & $130-450$ \\
\hline Leukocytes $\left(\mathrm{x} 10^{3} / \mu \mathrm{L}\right)$ & 46.2 & $4-10$ \\
\hline Neutrophils (x $\left.10^{3} / \mu \mathrm{L}\right)$ & 43 & $2.8-7.5$ \\
\hline Prothrombin time (s) & 16.3 & $8-14$ \\
\hline INR & 1.54 & $0.8-1.2$ \\
\hline Creatinine Kinase (U/L) & 2281 & $38-190$ \\
\hline CK-MMB (ng/mL) & 176.9 & $7-25$ \\
\hline Troponin I (ng/mL) & 24.58 & $<0.1$ \\
\hline Myoglobin (ng/mL) & 3131 & $28-72$ \\
\hline Creatinine (mg/dL) & 1.6 & $07-1.2$ \\
\hline Urea (mg/dL) & 120 & $17-50$ \\
\hline TGO (U/L) & 213 & $<38$ \\
\hline $\mathrm{Na}^{+}(\mathrm{mEq} / \mathrm{L})$ & 139 & $135-145$ \\
\hline $\mathrm{K}^{+}(\mathrm{mEq} / \mathrm{L})$ & 4 & $3.5-5$ \\
\hline $\mathrm{Cl}^{-}(\mathrm{mEq} / \mathrm{L})$ & 101 & $98-107$ \\
\hline CRP (mg/dL) & 17.66 & $<0.3$ \\
\hline
\end{tabular}

INR: International normalized ratio; s: seconds; CRP: C-reactive protein

$500 \mathrm{ppm}$. Inhalation of concentrations superior to $1000 \mathrm{ppm}$ results in immediate fatal situation ("knock down") [4].

The precise nature of the toxic agent in this case remains uncertain since $\mathrm{H}_{2} \mathrm{~S}$ laboratorial quantification was not avail- able in our setting. Nevertheless, $\mathrm{H}_{2} \mathrm{~S}$ has been described has the major toxic compound in sewer gas and the clinical picture was compatible to previously reported cases in literature [2-5].

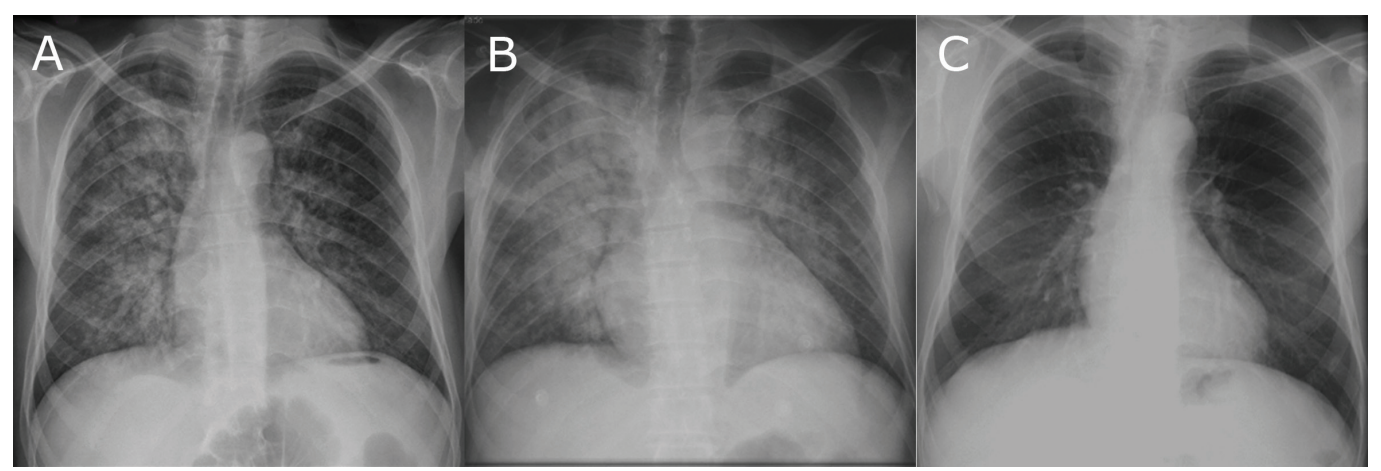

Figure 1. Chest-X ray serial imaging. (A) On admission, showing a predominant right sided heterogeneous lung infiltrate; (B) on the 7th in-hospital day revealing an aggravating lung injury; (C) On 3 months reassessment, documenting regression of the lung lesions. 


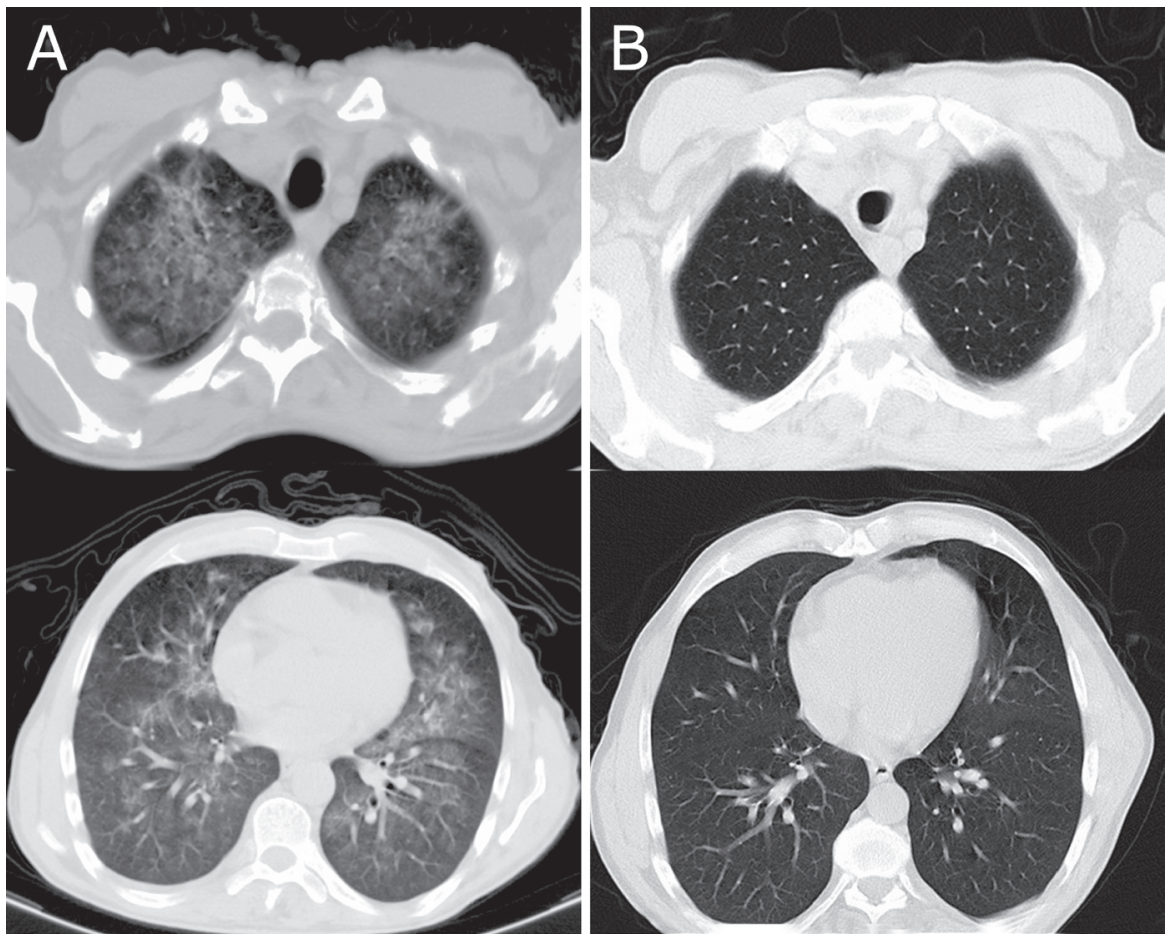

Figure 2. Lung CT scan serial images revealing a diffuse ground glass pattern with peribronchovascular bilateral infiltrate on admission (A) and significant reversal of lung lesions on follow-up at 3 months (B).

Toxicological analysis of sulfide or thiosulphate (a metabolite of sulfide) in blood and urine of the patient would have been useful to definitely determine the poisoning substance and monitor the clinical course. However, these specific laboratorial assessments are not readily available in Portuguese hospitals.

Left ventricular systolic dysfunction has been suggested as a possible cause for the cardio-respiratory complications [13]. Probably both pulmonary reactive pneumonitis and cardiogenic oedema contribute to the initial picture.

Neurological impact varies from headaches to convulsions, coma and respiratory arrest [13]. Alterations in consciousness state may be due to cerebral oedema and ischemia affecting the cerebral cortex and hippocampus. Delayed neuropsychiatric sequelae may affect motor function, memory, vision and hearing [15]. Some authors argue that neuropsychological testing is a key issue in neurotoxicology assessment because conventional neurology has been shown to be insensitive to the chemical neurotoxic effects and neuroimaging techniques are often unclear [16].

No management guidelines addressing $\mathrm{H}_{2} \mathrm{~S}$ poisoning are available. Currently, treatment approach is not evidencebased (as in most toxicological hazards) and shares some features with the approach to cyanogens poisoning. The most well described and used therapy is nitrite therapy, including 3\% sodium nitrite or amyl nitrate, which are more effective if administered soon post-exposure. In one case report, the authors hypothesize that repetitive intravenous administration of sodium nitrite is effective in cases of hydrogen sulfide exposure [17].

Anecdotal reports have mentioned the prompt use of hyperbaric oxygen therapy or hydroxocobalamin but these options remain controversial $[18,19]$.

Hyperbaric oxygen therapy may act by a competitive mechanism against $\mathrm{H}_{2} \mathrm{~S}$ at the level of cytochrome oxydase $[6,20]$ and may have a role in the prevention of both short and long-term neurological sequelae [19].

Hydroxocobalamin is believed to form a complex with $\mathrm{H}_{2} \mathrm{~S}$ in detoxification pathways. It has been widely described as an antidote for cyanide in smoke inhalation [21]. Decreased sulfide and thiosulphate concentration has been documented in a patient treated with hydroxocobalamin [17].

These additional therapies were not performed in this case since the patient arrived at the ED out of the therapeutic window of nitrites effectiveness and showed global improvement with the aforementioned supportive measures.

\section{Conclusion}

Exposure to sewer gas should recall the strong possibility of $\mathrm{H}_{2} \mathrm{~S}$ poisoning and medical teams approaching such scenarios must ensure adequate protective safety procedures.

Immediate treatment strategy relies in clinical presumption since laboratorial tests to identify sulfide compounds are not readily available.

$\mathrm{H}_{2} \mathrm{~S}$ direct toxicity and subsequent cellular hypoxic in- 
duction may rapidly lead to multi-organic dysfunction and death depending on the level of gas exposure.

Treatment options based on case reports options may include nitrites, hyperbaric oxygen therapy, and hydroxocobalamin. Decisions must be adapted to each case depending on the timing of post-exposure medical approach and severity of organ dysfunctions. However, the mainstay of care relies mainly in early supportive measures.

In our perspective, an urgent need exists for better scientific data. While more research is needed to establish appropriate treatment guidelines, occupational preventive measures are fundamental to avoid this highly lethal poisoning.

In the field of toxicology, and due to the relatively rare occurrence of poisonings, a comparative-effectiveness research is difficult to accomplish. A solution to improve the degree of evidence-based treatments could result from an international collaborative effort to set up a registry on toxicological hazards. In addition, it would be recommendable that national health systems include well-prepared toxicological protocols in order to avoid unnecessary delays and obstacles in identification, monitoring, and treatment of poisonings.

\section{Consent}

Written informed consent was obtained from the patient for publication of this case report and any accompanying images. A copy of the written consent is available for review by the Editor-in-Chief of this journal.

\section{Authors' Contributions}

DS gather all the data and wrote the main draft of the case report. NC actively participated in the manuscript elaboration, conceptual organization and revision. NC and GB were involved in patient approach at the Emergency Room. GB provided important remarks from patient management and data review. AP and MM helped in retrieving literature references and helped in English language corrections. $\mathrm{CM}, \mathrm{ME}$ and $\mathrm{AD}$ supervised the writing after reviewing the first versions and gave the final approval of the version to be publishing. All authors read and approved the final manuscript.

\section{Conflicts of Interest}

The authors declare that they have no competing interests.

\section{References}

1. Watt MM, Watt SJ, Seaton A. Episode of toxic gas exposure in sewer workers. Occup Environ Med. 1997;54(4):277-280.

2. Burnett WW, King EG, Grace M, Hall WF. Hydrogen sulfide poisoning: review of 5 years' experience. Can Med Assoc J. 1977;117(11):1277-1280.

3. Milby TH. Hydrogen sulfide intoxication. Review of the literature and report of unusual accident resulting in two cases of nonfatal poisoning. J Occup Med. 1962;4:431-437.

4. Morii D, Miyagatani Y, Nakamae N, Murao M, Taniyama K. Japanese experience of hydrogen sulfide: the suicide craze in 2008. J Occup Med Toxicol. 2010;5:28.

5. Vannatta JB. Hydrogen sulfide poisoning. Report of four cases and brief review of the literature. J Okla State Med Assoc. 1982;75(2):29-32.

6. Belley R, Bernard N, Cote M, Paquet F, Poitras J. Hyperbaric oxygen therapy in the management of two cases of hydrogen sulfide toxicity from liquid manure. CJEM. 2005;7(4):257-261.

7. Knight LD, Presnell SE. Death by sewer gas: case report of a double fatality and review of the literature. Am J Forensic Med Pathol. 2005;26(2):181-185.

8. Kirkhorn SR, Garry VF. Agricultural lung diseases. Environ Health Perspect. 2000;108 Suppl 4:705-712.

9. Guidotti TL. Occupational exposure to hydrogen sulfide in the sour gas industry: some unresolved issues. Int Arch Occup Environ Health. 1994;66(3):153-160.

10. Predicala B, Nemati M, Stade S, Lague C. Control of $\mathrm{H} 2 \mathrm{~S}$ emission from swine manure using Na-nitrite and Na-molybdate. J Hazard Mater. 2008;154(1-3):300-309.

11. Kim KY, Ko HJ, Kim HT, Kim YS, Roh YM, Lee CM, Kim CN. Monitoring of aerial pollutants emitted from Swine houses in Korea. Environ Monit Assess. 2007;133(1-3):255-266.

12. Amino M, Yoshioka K, Suzuki Y, Uemura S, Sakurai K, Fukushima T, Morita S, et al. Improvement in a patient suffering from cardiac injury due to severe hydrogen sulfide poisoning: a long-term examination of the process of recovery of heart failure by performing nuclear medicine study. Intern Med. 2009;48(19):1745-1748.

13. Chaari A, Bahloul M, Chelly H, Sahnoun M, Bouaziz M. Neurological and heart failure following an accidental intoxication by hydrogen sulphide: a case report. Ann Fr Anesth Reanim. 2010;29(4):304-307.

14. Oliveira, A.I.C., Intoxicação por Fumos de Incêndio em Portugal. Análise Casuística. Implicações MédicoLegais. 2011, Instituto de Ciências Biomédicas Abel Salazar - University of Porto: Porto. p. 154.

15. Tvedt B, Edland A, Skyberg K, Forberg O. Delayed neuropsychiatric sequelae after acute hydrogen sulfide poisoning: affection of motor function, memory, vision and hearing. Acta Neurol Scand. 1991;84(4):348-351.

16. Fenga C, Cacciola A, Micali E. Cognitive sequelae of acute hydrogen sulphide poisoning. A case report. Med Lav. 2002;93(4):322-328. 
17. Fujino $\mathrm{Y}$, Inoue $\mathrm{Y}$, Onodera $\mathrm{M}$, Kikuchi S, Endo J, Endo S, Fujita Y. Case followed by delayed loss of consciousness after exposure to hydrogen sulfide that was treated with intermittent administration of sodium nitrite. Chudoku Kenkyu. 2010;23(4):297-302.

18. Fujita Y, Fujino Y, Onodera M, Kikuchi S, Kikkawa $\mathrm{T}$, Inoue $\mathrm{Y}$, Niitsu $\mathrm{H}$, et al. A fatal case of acute hydrogen sulfide poisoning caused by hydrogen sulfide: hydroxocobalamin therapy for acute hydrogen sulfide poisoning. J Anal Toxicol. 2011;35(2):119-123.
19. Gunn B, Wong R. Noxious gas exposure in the outback: two cases of hydrogen sulfide toxicity. Emerg Med (Fremantle). 2001;13(2):240-246.

20. Smilkstein MJ, Bronstein AC, Pickett HM, Rumack BH. Hyperbaric oxygen therapy for severe hydrogen sulfide poisoning. J Emerg Med. 1985;3(1):27-30.

21. Borron SW, Baud FJ, Barriot P, Imbert M, Bismuth C. Prospective study of hydroxocobalamin for acute cyanide poisoning in smoke inhalation. Ann Emerg Med. 2007;49(6):794-801, 801 e791-792. 